\title{
Changes in milk lactose content as indicators for longevity and udder health in Holstein cows
}

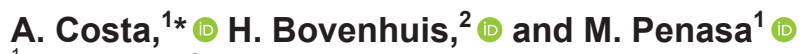 \\ ${ }^{1}$ Department of Agronomy, Food, Natural resources, Animals and Environment, University of Padova, Viale dell'Università 16, \\ 35020 Legnaro (PD), Italy \\ ${ }^{2}$ Animal Breeding and Genomics Group, Wageningen University, PO Box 338, $6700 \mathrm{AH}$, Wageningen, the Netherlands
}

\begin{abstract}
Changes in milk production traits over time might be informative of the health status of cows and may contain useful information for selective breeding purposes. In particular, early indicators are useful for traits such as longevity, which become available late in the cow's life. Lactose percentage (LP) tends to decrease in the presence of udder infection and with parity. Therefore, it can be hypothesized that cows exhibiting limited changes in LP across lactations have experienced fewer udder infections in their productive life and have a higher chance to stay longer in the herd than cows with more pronounced reduction of LP across lactations. In this study, 9 descriptors of change in LP during a cow's lifetime were defined and evaluated as potential indicators for selective breeding. For the purpose of this study, test-day records of the first 44 days in milk (DIM) of each lactation were discarded, and cows were required to have at least 5 test-days/cow per lactation ( $\geq 45$ DIM) over the first 3 lactations. In this study, descriptors of LP were available for 69,586 Italian Holstein cows. Changes in LP in each lactation were quantified by regressing LP on DIM; thus, $\beta_{1}, \beta_{2}$, and $\beta_{3}$ represented the changes in LP within lactations 1,2 , and 3, respectively. Changes in LP across multiple lactations were also quantified by regressing LP on DIM (with exclusion of the first 44 DIM of each lactation); briefly, $\beta_{12}$ was the change of LP over lactation 1 and $2, \beta_{23}$ was the change of LP over lactation 2 and 3 , and $\beta_{123}$ was the change of LP over lactation 1,2 , and 3 . Alternatively, changes in the LP lactation means $(\Delta)$ were quantified between lactations 1 and $2\left(\Delta_{12}\right), 2$ and $3\left(\Delta_{23}\right)$, and 1 and $3\left(\Delta_{13}\right)$. For comparison, $\beta$ and $\Delta$ were also derived for milk yield $(\mathrm{kg} / \mathrm{d})$, somatic cell score, and log-transformed total somatic cells excreted daily in milk (units). Variance components and esti-
\end{abstract}

Received March 30, 2020.

Accepted July 20, 2020.

*Corresponding author: angela.costa@unipd.it mated breeding values (EBV) for all $\beta$ 's and $\Delta$ 's were estimated. In addition, EBV for bulls with at least 25 daughters were used to assess Calo's genetic correlations between descriptors of change in LP with official published EBV for functional traits. Heritabilities for $\beta$ and $\Delta$ of LP ranged from $0.06\left(\Delta_{23}\right)$ to $0.20\left(\Delta_{13}\right)$, and differed significantly from 0 . Furthermore, LP $\mathrm{EBV}$ for $\beta$ and $\Delta$ were correlated with official EBV for functional longevity index, udder health index, udder score (mammary gland morphology) index, and milk persistency; Calo's genetic correlations of LP $\beta_{123}$ with functional longevity and udder health index were 0.52 and 0.33 , respectively. Cows with a stronger reduction of LP across lactations (i.e., stronger and negative $\beta$, and greater and positive $\Delta$ ) were characterized by lower milk persistency, impaired longevity, and worse udder health and morphology than cows with smaller reduction in LP across lactations. Results highlighted that changes in milk LP have the potential to be exploited as indicators for functional traits in Italian Holstein cattle. Further research on the biological relationship between changes in LP and mastitis is recommended. Key words: lactose, trend, indicator, udder health, breeding

\section{INTRODUCTION}

Milk yield (MY) and its composition are important sources of information for dairy cattle breeding and management. In addition to reflecting quality, milk composition mirrors the metabolic and clinical status of the cow (Egger-Danner et al., 2015; Grelet et al., 2019). In recent years, emphasis of breeding goals have moved from milk production to non-production traits such as cow fertility, health, welfare, and efficiency (Cole and VanRaden, 2018). Phenotyping for such features is often difficult, expensive, and time-consuming; thus, correlated and easy-to-measure indicator traits are attractive for large-scale genetic evaluation. For example, the fat-to-protein ratio of milk is used as a marker for negative energy balance and ketosis, and SCS is used 
to monitor udder health and susceptibility to IMI. The pattern of some traits can be informative of cow health and efficiency; for instance, the change in MY from parity 1 to 3 has been suggested as an indicator of maturity (de Jong, 2014), while the change in MY within a lactation represents the persistency (Interbull, 2020). Recently, fluctuations in longitudinal MY records have been suggested as indicators of resilience (Berghof et al., 2019; Poppe et al., 2020).

Among routinely collected milk traits, lactose percentage (LP) shows very little variation (Costa et al., 2019b). Despite this, changes in LP over parities are relatively large, with the highest concentrations of LP in parity 1 , and a progressive decrease in subsequent lactations (Miglior et al., 2007; Haile-Mariam and Pryce, 2017; Costa et al., 2019b). The low variability of milk LP is due to physiological reasons; lactose is the major compound that determines milk osmolality, and hence is bound by biological constraints. However, biological explanations for the decrease of LP over subsequent parities have not been described thus far. It can be hypothesized that the lifetime decrease of LP is the result of accumulated effects of IMI on mammary gland epithelium and that LP consequently mirrors the infection history of the mammary gland. This would agree with the observation that milk of multiparous cows is characterized by higher SCC compared with milk of primiparous (Jamali et al., 2018). In addition, negative genetic and phenotypic correlations exist between LP and SCS (Haile-Mariam and Pryce, 2017; Costa et al., 2019b,c), and between LP and mastitis (Costa et al., 2019a). Therefore, the change in milk LP during a cow's lifetime might be considered a "mammary memory indicator." In the present study, 9 descriptors (hereby "indicators") of such change in milk LP were calculated for the first 3 lactations of Italian Holstein cows. Furthermore, to investigate their potential use in selective breeding, heritabilities and correlations of LP indicators with functional traits were estimated.

\section{MATERIALS AND METHODS}

\section{Data Editing}

A data set consisting of 4,211,494 milk test-day records (TD) collected on 299,227 Italian Holstein cows from January 2002 to September 2018 during routine milk recording was retrieved from the Italian Holstein and Jersey Breeders Association (ANAFIJ, Cremona, Italy). Parity ranged from 1 to 3 , and DIM ranged from 5 to 305 . Cows with age at calving that deviated more than 5 standard deviations (SD) from the respective parity mean, and with calving interval lower than 10 mo or longer than mean \pm 15 mo, were dis- carded. The calving interval between first and second calving averaged $14.0 \pm 3.0 \mathrm{mo}$, and between second and third calving averaged $14.3 \pm 3.1$ mo. Cows were discarded when both parents were unknown and if they changed herd during the period considered. Moreover, only herds with at least 5 cows were kept. Values of LP and MY deviating more than 5 SD from the mean were removed from the data set, as well as values of SCC outside the range of 1,000 to $10,000,000$ cells/ $\mathrm{mL}$. For the purpose of the present study, cows were retained when they had $\geq 5$ TD for MY $(\mathrm{kg} / \mathrm{d})$, LP (\%), and SCC records (cells $/ \mathrm{mL}$ ) in each of the 3 lactations. There were $3,435,140$ TD of 69,586 cows in 739 herds left for subsequent analyses after editing. Milk SCC were transformed to SCS as follows: SCS $=3+$ $\log _{2}(\mathrm{SCC} / 100,000)$. The total number of somatic cells excreted in milk daily (TSCC; cells/d) was calculated by multiplying SCC and MY, where MY was converted to $\mathrm{mL} / \mathrm{d}$ as described in Fox et al. (2015):

$$
\operatorname{MY}(\mathrm{mL} / \mathrm{d})=[\mathrm{MY}(\mathrm{kg} / \mathrm{d}) / 1.03(\mathrm{~kg} / \mathrm{L})] \times 1,000
$$

Finally, TSCC was transformed to total SCS (TSCS; units) to achieve a Gaussian distribution of the data as TSCS $=\log _{2}$ (TSCC).

\section{Definition of the Indicators}

The changes in LP were quantified based either on regression of LP records on DIM (slope; $\beta$ ) or on changes in lactation mean LP (delta; $\Delta$ ). Slopes were the regression coefficients of LP on DIM estimated within lactations $1\left(\beta_{1}\right), 2\left(\beta_{2}\right)$, and $3\left(\beta_{3}\right)$, and across lactations 1 and $2\left(\beta_{12}\right), 2$ and $3\left(\beta_{23}\right)$, and 1,2 , and $3\left(\beta_{123}\right)$; TD used for estimating slopes were within a window from 45 to 305 DIM. The cut-off at 45 DIM was set after visual inspection of data (Figure 1) and allowed us to exclude the effect of the LP increase usually observed during the initiation of lactation (from DIM 5 to 44) from the calculation of $\beta$. The $\beta_{1}, \beta_{2}$, and $\beta_{3}$ were estimated by regressing TD of the trait within a lactation (dependent variable) on untransformed DIM (independent variable). Instead, for $\beta_{12}, \beta_{23}$, and $\beta_{123}$, the regression analysis was performed on the transformed DIM. Transformation of DIM was required, as the first 44 DIM of each lactation were excluded (Figure 2). Transformed DIM were defined as:

$$
\begin{gathered}
\text { TDIM }_{1}=\mathrm{DIM}_{\mathrm{TD} 1}-44 \\
\mathrm{TDIM}_{2}=\mathrm{DIM}_{\mathrm{TD} 2}-44+(305-44) \\
\mathrm{TDIM}_{3}=\mathrm{DIM}_{\mathrm{TD} 3}-44+(305-44)+(305-44)
\end{gathered}
$$




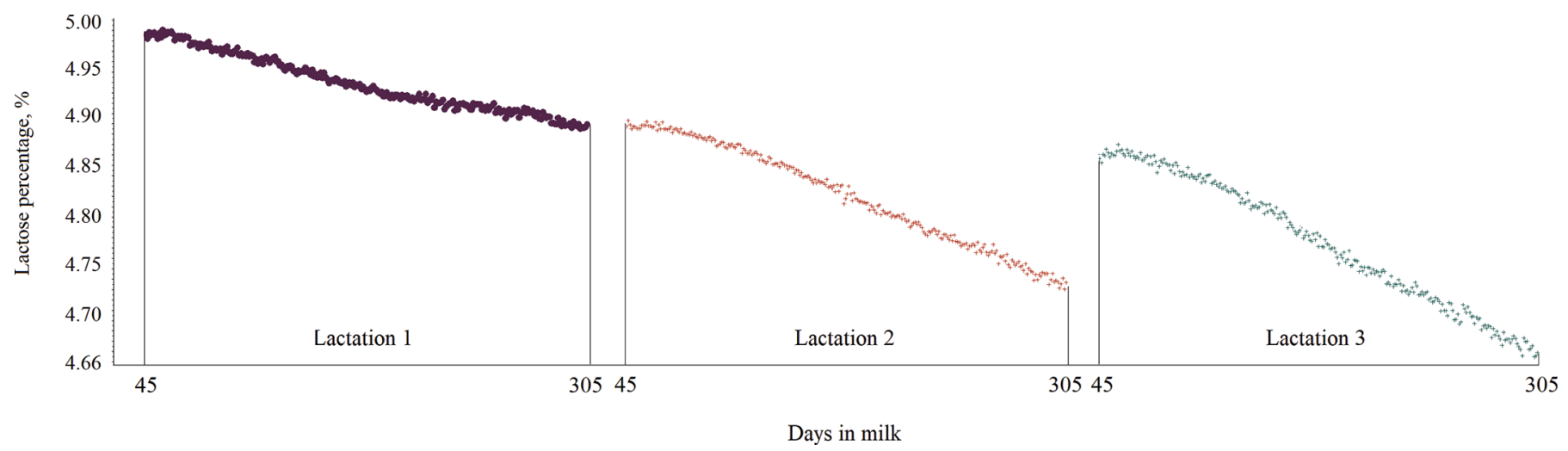

Figure 1. Lactation curves of lactose percentage for parity 1 to 3 after the cut-off at DIM 45 .

where $\mathrm{TDIM}_{1}, \mathrm{TDIM}_{2}$, and $\mathrm{TDIM}_{3}$ were the transformed DIM from lactations 1, 2, and 3, respectively, and $\mathrm{DIM}_{\mathrm{TD} 1}, \mathrm{DIM}_{\mathrm{TD} 2}$, and $\mathrm{DIM}_{\mathrm{TD} 3}$ were the original DIM of the TD of lactations 1, 2, and 3, respectively. For example, $\mathrm{DIM}_{\mathrm{TD} 1}=45$ was transformed to $\mathrm{TDIM}_{1}$ $=1 ; \mathrm{DIM}_{\mathrm{TD} 2}=45$ was transformed to $\mathrm{TDIM}_{2}=262$; $\mathrm{DIM}_{\mathrm{TD} 3}=45$ was transformed to $\mathrm{TDIM}_{3}=523$. Further, $3 \Delta$ were defined as:

$$
\Delta_{u v}=\bar{x}_{u}-\bar{x}_{v},
$$

where $\bar{x}_{u}$ and $\bar{x}_{v}$ are the averages of the LP in lactations $u$ and $v$, respectively, calculated from all TD available for that lactation (5-305 DIM). Therefore, $\Delta_{12}, \Delta_{13}$, and $\Delta_{23}$ represented the change in LP from lactations 1 to 2,1 to 3 , and 2 to 3 , respectively. For comparison, the same approach was adopted to derive indicators based on MY, SCS, and TSCS.

\section{Genetic Analysis}

Variance components and EBV for indicators based on LP, MY, SCS, and TSCS were assessed using a linear animal model in ASReml 4.1 software (Gilmour et al., 2015). To avoid convergence issues due to small variance component estimates, all $\beta$ values were multiplied by 1,000 . The fixed effects of the model differed according to the indicator analyzed:

$i$. For dependent variable $\beta_{1}$ :

$$
y_{i j k l}=\mu+Y S_{i}+b\left(a g e_{i j k l}\right)+a_{j}+h_{k}+e_{i j k l},
$$

where $\mu$ is the overall mean; $Y S$ is the fixed effect of year and season of calving, with season of calving defined as: winter (December to February), spring (March to May), summer (June to August), and fall (September to November); age is the fixed effect of calving age (mo) included as a covariate with regression coefficient $b$.

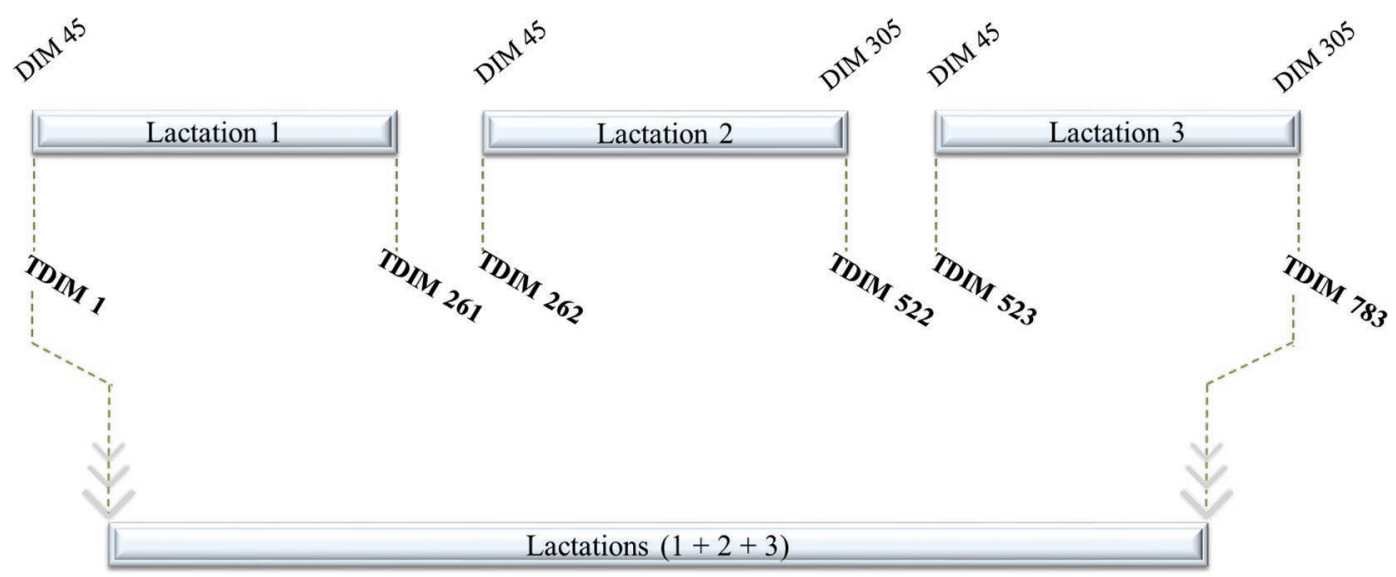
tion.

Figure 2. Scheme representing the conversion from DIM to transformed DIM (TDIM) used in the regression analyses for the slopes calcula- 
ii. For dependent variables $\beta_{2}$ and $\beta_{3}$ :

$$
\begin{aligned}
y_{i j k l}=\mu+ & Y S_{i}+b_{1}\left(a g e_{i j k l}\right)+b_{2}\left(\operatorname{cint}_{i j k l}\right) \\
& +a_{j}+h_{k}+e_{i j k l},
\end{aligned}
$$

where $\mu$ is the overall mean; $Y S$ is the fixed effect of year and season of calving as described in model i; age is the fixed effect of calving age (mo) included as a covariate with regression coefficient $b_{1}$; cint is the fixed effect of calving interval (mo) included as a covariate with regression coefficient $b_{2}$.

iii. For dependent variables $\beta_{12}, \beta_{23}, \Delta_{12}$, and $\Delta_{23}$ :

$$
\begin{aligned}
y_{i j k l m}=\mu & +Y S 1_{i}+Y S 2_{j}+b_{1}\left(\text { age }_{i j k l m}\right)+b_{2}\left(a g e \mathscr{2}_{i j k l m}\right) \\
& +b_{3}\left(\text { cint12 } 2_{i j k l m}\right)+a_{k}+h_{l}+e_{i j k l m},
\end{aligned}
$$

where $\mu$ is the overall mean; YS1 and YS2 are the fixed effects of year and season of the calvings as described in model $i$; age 1 and age 2 are the fixed effects of age (mo) at the calvings included as covariates with regression coefficients $b_{1}$ and $b_{2}$; cint is the fixed effect of the calving interval (mo) between 2 consecutive calvings included as a covariate with regression coefficient $b_{3}$.

$i v$. For dependent variables $\beta_{123}$ and $\Delta_{13}$ :

$$
\begin{gathered}
y_{i j k l}=\mu+Y S 123_{i}+b_{1}\left(\text { age }_{i j k l}\right)+b_{2}\left(\text { age }_{i j k l}\right) \\
+b_{3}\left(\text { age }_{i j k l}\right) \\
+b_{4}\left(\text { cint1 }_{i j k l}\right)+b_{5}\left(\text { cint2 }_{i j k l}\right) \\
+a_{j}+h_{k}+e_{i j k l},
\end{gathered}
$$

where $\mu$ is the overall mean; YS123 is the fixed effect of year and season of calving in parity 1,2 , and 3 , as described in model $i$; age1, age2, and age 3 are the fixed effects of age (mo) at first, second, and third calvings included as covariates with regression coefficients $b_{1}$, $b_{2}$, and $b_{3}$; cint12 and cint23 are the fixed effects of the 2 calving intervals (mo) included as covariates with regression coefficients $b_{4}$ and $b_{5}$.

All models accounted for the random effects of additive genetic animal $(a)$, herd $(h)$, and residual $(e)$, which were assumed to be distributed as $a \sim N\left(0, \mathbf{A} \sigma_{a}^{2}\right)$, $h \sim N\left(0, \mathbf{I} \sigma_{h}^{2}\right)$, and $e \sim N\left(0, \mathbf{I} \sigma_{e}^{2}\right)$, where $\sigma_{a}^{2}, \sigma_{h}^{2}$, and $\sigma_{e}^{2}$ denote additive genetic, herd, and residual variances, $\mathbf{A}$ is the pedigree-based additive genetic relationship matrix, and $\mathbf{I}$ is an identity matrix of appropriate order. The matrix $\mathbf{A}$ included cows with phenotypes (offspring of 6,434 sires and 59,723 dams) and 5 generations of ancestors, resulting in a pedigree of 246,023 animals. Genetic parameters and EBV were also calcu- lated for lactation average LP in parity 1 (model $i$ ), 2 (model ii), and 3 (model ii). Finally, the intraherd heritability $\left(h_{I H}^{2}\right)$ of each indicator was calculated to quantify the genetic variation among animals within herds (Heringstad et al., 2006; Stoop et al., 2008):

$$
h_{I H}^{2}=\left(\frac{\sigma_{a}^{2}}{\sigma_{a}^{2}+\sigma_{e}^{2}}\right) .
$$

\section{Correlations}

The ANAFIJ (Cremona, Italy) provided official sires' EBV standardized to mean of 100 and SD of 5 for functional longevity index, udder health index, udder score index, milk persistency, and SCS index estimated during the August 2018 routine genetic evaluation, along with their reliability. The functional longevity index combines EBV for direct longevity with EBV for feet and legs and udder morphology (ANAFIJ, 2019). Direct longevity is defined as the risk of involuntary culling during a cow's lifetime, and EBV are obtained using survival analysis by applying a proportional hazard function following a Weibull distribution with correction for the productivity level (ANAFIJ, 2019; Interbull, 2020). The udder health index includes information from different first-lactation traits: average SCS from 5 to 150 DIM, SD of SCS of the entire lactation, the ratio of the number of SCC records $>400,000$ cells/ $\mathrm{mL}$ to the total number of records within lactation, and number of SCC peaks within lactation (ANAFIJ, 2019). The udder score index refers to mammary gland morphology and combines EBV for several udder conformation traits scored during first lactation (ANAFIJ, 2019): fore udder attachment, rear udder width, central ligament, udder depth, and front teats position. Milk persistency is calculated within each lactation from the EBV for milk production at 280 DIM and the EBV for milk production at 60 DIM, both obtained from TD random regression analysis, and the final EBV is the weighted sum of persistency of first $(50 \%)$, second (25\%), and third lactations (25\%; ANAFIJ, 2019). Finally, the EBV for SCS index (SCS_I) is based on the EBV of SCC of first, second, and third lactations, each with equal weight (33.3\%; ANAFIJ, 2019). For all the official EBV described, values greater than 100 are preferred.

Genetic correlations of LP indicators with official EBV were approximated by calculating weighted correlations between EBV using the formula of Calo et al. (1973): 


$$
r_{C}=\frac{\sqrt{\left(\sum r e l_{A}\right) \times\left(\sum r e l_{B}\right)}}{\sum\left(\mathrm{rel}_{A} \times r e l_{B}\right)} \times r_{\text {Pearson }}
$$

where $r_{C}$ is the Calo's genetic correlation between EBV of trait A (LP indicator) and trait B (functional longevity index, udder health index, udder score index, milk persistency, and SCS_I); $r e l_{A}$ and $r e l_{B}$ are the reliabilities of the EBV for traits A and $\mathrm{B} ; r_{\text {Pearson }}$ is the Pearson correlation between EBV of traits A and B. Only bulls with at least 25 daughters in the current data set $(\mathrm{n}=378)$ were included in the calculations. The reliability of the EBV for the indicators was calculated as:

$$
r e l=1-\frac{P E V}{\sigma_{a}^{2}},
$$

where rel is the reliability of EBV, and $P E V$ is the prediction error variance of the EBV.

\section{Selection Response}

To compare the values of different indicators for selection, the relative selection efficiency $(R E)$ was calculated. Given that bulls are progeny tested and selected based on the indicator trait $y$, the correlated response $\left(R_{x}\right)$ for the breeding-goal trait $x$ is:

$$
R_{x}=i \times r_{a} \times \sqrt{\frac{1 / 4 n \times h_{y}^{2}}{1+1 / 4(n-1) \times h_{y}^{2}}} \times \sigma_{a_{x}},
$$

where $i$ is the selection intensity; $r_{a}$ is the genetic correlation between $y$ and $x ; n$ is the number of daughters with information on $y ; h_{y}^{2}$ is the heritability of indicator trait $y ; \sigma_{a_{x}}$ is the additive genetic SD of breedinggoal trait $x$. Assuming both $i$ and $\sigma_{a_{x}}$ are identical for different indicators and that $\mathrm{n}=75$, the $R E$ for breeding-goal trait $x$ can be estimated for different indicators, as:

$$
R E=\left|r_{a}\right| \times \sqrt{\frac{1 / 4 n \times h_{I N D}^{2}}{1+1 / 4(n-1) \times h_{I N D}^{2}}},
$$

where $h_{I N D}^{2}$ is the heritability of the indicator trait.

\section{RESULTS AND DISCUSSION}

\section{Descriptive Statistics}

Milk LP decreased with parity, whereas MY, SCS, and TSCS increased (Table 1). The LP decreased by 0.17 from lactation 1 to 3 (Table 1); this reduction is greater than the $\mathrm{SD}$ of LP in lactations $1(\mathrm{SD}=0.14)$, $2(\mathrm{SD}=0.15)$, and $3(\mathrm{SD}=0.16)$. Overall, results were comparable to findings of Miglior et al. (2007) for Canadian Holsteins, who reported a decrease in LP of 0.18 from lactation 1 to lactation 3 (i.e., from 4.71 to $4.53 \%$ ). The decrease of LP across parities has also been reported for other cattle breeds (Gottardo et al., 2017; Costa et al., 2019a). Considering the physiological role of lactose in milk, LP is expected to be rather constant. However, the LP drop observed might be attributed to an increased mastitis incidence in multiparous cows and to the cumulative effect of IMI during the productive life. In fact, the chance to experience an IMI during a lactation is 15 times greater for third- than for first-lactation cows (Pinzón-Sánchez and Ruegg, 2011). Cows experiencing IMI show an increased permeability of the epithelium of the alveolar structures due to action of bacteria and immune-response related factors, such as cytokines and oxidative bodies (Akers and Nickerson, 2011; Costa et al., 2019b). In fact, the latter are responsible for the damage of tight junctions and epithelium surrounding alveoli during and after IMI (Zhao and Lacasse, 2008; Costa et al., 2019b). As soon as the epithelial permeability is compromised, the lactose in the alveoli is lost in the blood and disposed of in the urine, and thus milk LP is reduced (Costa et al., 2019b). For this reason, plasma LP has been proposed as an indicator of alveolar integrity in cows (Herve et al., 2019). Alternatively, one could argue that the progressive reduction of alveolar integrity and drop of LP in later lactations is due to a lower cell-turnover rate that characterizes aging cows. When damaged or apoptotic epithelial cells are not entirely replaced after IMI or during the dry period, there might be a lasting effect of IMI. The latter may be more evident in high-producing cows under high oxidative stress (Capuco and Choudhary, 2020), which is a relevant risk factor for IMI susceptibility and udder tissue integrity (Jóźwik et al., 2012; Jin et al., 2016; Bae et al., 2017). However, mechanisms responsible for cell apoptosis and mammary epithelium renewal are not well understood in dairy cattle (Zhao and Lacasse, 2008; Capuco and Choudhary, 2020).

Neither direct diagnoses of clinical and subclinical mastitis by farmers and veterinarians, nor data on 
Table 1. Mean and CV (\%, in brackets) for lactose percentage (LP, \%), milk yield (MY, kg/d), SCS (units), and score of total somatic cells daily excreted in milk (TSCS, ${ }^{1}$ units) in the first 3 lactations

\begin{tabular}{lcccc}
\hline Lactation & LP & MY & SCS & TSCS \\
\hline 1 & $4.95(2.8)$ & $29.5(18.0)$ & $2.59(49.1)$ & $21.00(6.0)$ \\
2 & $4.84(3.1)$ & $32.7(20.0)$ & $2.98(47.3)$ & $21.52(6.4)$ \\
3 & $4.78(3.3)$ & $33.7(20.8)$ & $3.47(45.3)$ & $22.05(7.0)$ \\
\hline
\end{tabular}

${ }^{1} \mathrm{TSCS}=\log _{2}(\mathrm{SCC} \times \mathrm{MY})$, where $\mathrm{SCC}$ is expressed in cells $/ \mathrm{mL}$ and $\mathrm{MY}$ in $\mathrm{mL} / \mathrm{d}$.

bacteria responsible for udder IMI were available for this study; thus, it was not possible to distinguish the effect of cumulative experienced IMI from the effect of natural aging. The damage related to cumulative IMI consisted of an increase of dead cells, scar tissue formation, and weaker tight junctions. This causes part of the synthesized lactose to be lost in the blood stream, and subsequently in the urine (Shuster et al., 1991; Herve et al., 2019). Finally, oxytocin, the hormone acting on myoepithelial cells in charge of milk ejection, is reported to have a detrimental effect on epithelial integrity in the long term (Herve et al., 2018). This means that the effect of milking in prolonged lactations, coupled with suboptimal milking practices (e.g., overmilking), could be responsible for epithelial disruption, and thus indirectly for the LP drop (Herve et al., 2018).

The coefficient of variation $(\mathbf{C V})$ tended to increase with parity for LP, MY, and TSCS, whereas the CV of SCS decreased (Table 1). This highlighted that, for both LP and SCS, the variation increased when the average decreased and vice versa. In lactation 3 the $\mathrm{CV}$ of LP was the greatest and the average was the least compared with previous lactations (Table 1). This is in contrast with the common observation that variation increases with the average.

\section{Lactose Percentage Changes as Indicators}

Mean, phenotypic variance, and heritability of LP indicators are reported in Table 2; all 9 of the descriptors of changes in LP were normally distributed. Slopes of LP were on average negative, describing the decrease of LP across lactations. The lowest mean $\beta$ was observed for $\beta_{3}(-0.838)$, which corresponded with the greatest LP drop. The means of $\Delta$ were positive, which is a consequence of the definition of $\Delta$ and the decrease of LP across lactations. The SD of both $\beta$ and $\Delta$ were often larger than the mean (Table 2). This indicated that a substantial number of cows showed small changes in LP (Garg, 2015). For instance, part of cows ( $\mathrm{n}=$ $4,020)$ exhibited $\beta_{123}$ close to zero (between -0.0001 and +0.0001 ), indicating that LP was rather constant over the 3 lactations in such animals.
The largest heritabilities were estimated for $\Delta_{13}$ $(0.20), \beta_{12}(0.19)$, and $\Delta_{12}(0.16)$, and all heritability estimates differed significantly from 0 . These findings showed that part of the variation observed in the LP indicators have a genetic basis. Heritability of indicators based on LP change are lower than heritabilities reported for LP in Holstein cows (0.24-0.64; Costa et al., 2019b).

The EBV of LP indicators were related to official EBV for functional longevity index, udder health and morphology index, milk persistency, and SCS_I (Table 3). In particular, smaller changes in LP (reduced $\beta$ and smaller $\Delta$ ) were associated with prolonged productive life, a healthier mammary gland, better udder morphology, greater persistency, and favorable milk SCS_I. Miglior et al. (2007) estimated favorable correlations between EBV of LP with EBV of lifetime profit index (0.139), udder depth (0.128), milk persistency (0.329), and SCS index $(-0.164)$ in Canadian Holsteins. The same authors also observed greater risk of culling in cows with low milk LP (Miglior et al., 2006). In the current study, $\mathrm{r}_{\mathrm{C}}$ for lactation average $\mathrm{LP}$ with the index traits were weaker than those calculated for some LP indicators (results not shown). In particular, correlations of $\beta_{12}, \beta_{123}$, and $\Delta_{12}$ of LP with functional longevity index (Table 3) were stronger than correlations between lactation averages of LP and functional longevity

Table 2. Mean, phenotypic variance $\left(\sigma_{\mathrm{p}}^{2}\right)$, and heritability of traits describing changes over time in lactose percentage ${ }^{1}$; standard errors of heritability estimates were $<0.01$

\begin{tabular}{lccc}
\hline Trait & Mean $(\mathrm{SD})$ & $\sigma_{\mathrm{p}}^{2}$ & Heritability \\
\hline$\beta_{1}$ & $-0.318(0.772)$ & 0.59 & 0.11 \\
$\beta_{2}$ & $-0.600(0.942)$ & 0.87 & 0.13 \\
$\beta_{3}$ & $-0.838(1.084)$ & 1.16 & 0.12 \\
$\beta_{12}$ & $-0.435(0.374)$ & 0.14 & 0.19 \\
$\beta_{123}$ & $-0.038(1.456)$ & 2.06 & 0.12 \\
$\beta_{23}$ & $-0.321(0.389)$ & 0.15 & 0.11 \\
$\Delta_{12}$ & $0.111(0.103)$ & 0.01 & 0.16 \\
$\Delta_{13}$ & $0.166(0.126)$ & 0.02 & 0.20 \\
$\Delta_{23}$ & $0.054(0.112)$ & 0.01 & 0.06 \\
\hline
\end{tabular}

${ }^{1} \beta$ are slopes from a linear regression of the trait on DIM within or across lactations; $\Delta$ are deltas expressed as the difference between the means of the trait in the 2 lactations considered. All $\beta$ were multiplied by 1,000 to avoid convergence issues. 
(Haile-Mariam and Pryce, 2017); the same was true for other correlations, including the association between $\beta_{123}$ and udder health index. The $\mathrm{r}_{\mathrm{C}}$ of indicators based on LP with those of MY, SCS, and TSCS were also calculated (Table 4). Some LP indicators were genetically correlated with those of SCS and MY; negative $\mathrm{r}_{\mathrm{C}}$ were estimated between $\beta_{12}(-0.52)$ and between $\beta_{123}(-0.11)$ of LP and SCS, confirming the negative relationships between these traits. The indicators based on MY and LP were correlated and the $\mathrm{r}_{\mathrm{C}}$ ranged from $0.21\left(\beta_{1}\right)$ to $0.93\left(\beta_{123} ;\right.$ Table 4$)$.
The $\mathrm{r}_{\mathrm{C}}$ of MY, SCS, and TSCS indicators with functional longevity index, udder health and morphology index, milk persistency, and SCS_I are presented in Table 3; some of these $r_{C}$ were stronger than $r_{C}$ of LP indicators with the same traits. For example, the $\beta_{12}$ of MY was more strongly correlated with functional longevity index than $\beta_{12}$ of LP. Results suggested that in some cases the indicators based on MY and LP captured the same variation of a trait. However, indicators based on MY, SCS, and TSCS were less heritable than those based on LP (Table 2 and Table 5).

Table 3. Calo's correlations of bulls' EBV of traits describing changes over time ${ }^{1}$ in lactose percentage (LP), milk yield (MY, kg/d), SCS (units), and score of total somatic cells daily excreted in milk $\left(\mathrm{TSCS}^{2}\right.$, units) with official EBV for some functional traits ${ }^{3}$; each bull $(\mathrm{n}=378)$ had at least 25 daughters

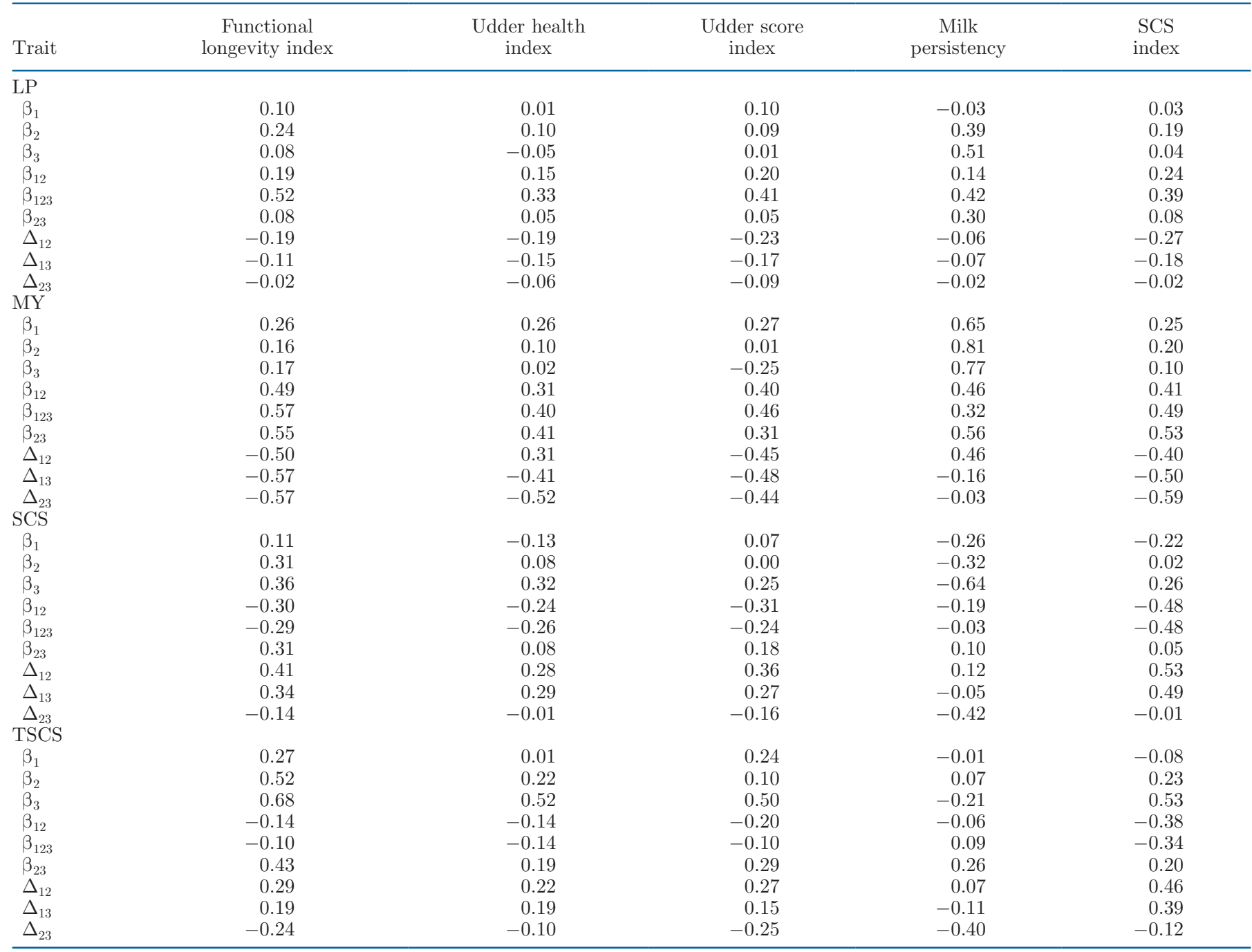

${ }^{1} \beta$ are slopes from a linear regression of the trait on DIM within or across lactations; $\Delta$ are deltas expressed as the difference between the means of the trait in the 2 lactations considered. All $\beta$ were multiplied by 1,000 to avoid convergence issues.

${ }^{2} \mathrm{TSCS}=\log _{2}(\mathrm{SCC} \times \mathrm{MY})$, where SCC is expressed in cells $/ \mathrm{mL}$ and $\mathrm{MY}$ in $\mathrm{mL} / \mathrm{d}$.

${ }^{3}$ From the August 2018 routine genetic evaluation performed by the Italian Holstein and Jersey Breeders Association (ANAFIJ, 2019). 
Table 4. Calo's correlations between bulls' EBV of traits describing changes over time in lactose percentage (LP) with EBV of traits describing changes over time in milk yield (MY, kg/d), SCS (units), and score of total somatic cells daily excreted in milk (TSCS ${ }^{2}$, units); each bull $(\mathrm{n}=378)$ had at least 25 daughters

\begin{tabular}{lccc}
\hline Trait & LP-MY & LP-SCS & LP-TSCS \\
\hline$\beta_{1}$ & 0.21 & 0.06 & 0.16 \\
$\beta_{2}$ & 0.67 & -0.63 & -0.28 \\
$\beta_{3}$ & 0.72 & -0.90 & -0.69 \\
$\beta_{12}$ & 0.53 & -0.52 & -0.39 \\
$\beta_{123}$ & 0.93 & -0.11 & 0.33 \\
$\beta_{23}$ & 0.52 & -0.74 & -0.50 \\
$\Delta_{12}$ & 0.45 & -0.57 & -0.51 \\
$\Delta_{13}$ & 0.41 & -0.49 & -0.42 \\
$\Delta_{23}$ & 0.54 & -0.82 & -0.69 \\
\hline
\end{tabular}

${ }^{1} \beta$ are slopes from a linear regression of the trait on DIM within or across lactations; $\Delta$ are deltas expressed as the difference between the means of the trait in the 2 lactations considered. All $\beta$ were multiplied by 1,000 to avoid convergence issues.

${ }^{2} \mathrm{TSCS}=\log _{2}(\mathrm{SCC} \times \mathrm{MY})$, where $\mathrm{SCC}$ is expressed in cells $/ \mathrm{mL}$ and $\mathrm{MY}$ in $\mathrm{mL} / \mathrm{d}$.

\section{Implications for Selection}

The $R E$ depends on the heritability of the indicator trait and the correlation between the breeding-goal and the indicator trait. Indicators with the highest heritability in the present study were those of LP and MY; therefore, RE based on these traits were calculated for the following breeding-goal traits: functional longevity index, udder health index, udder score index, milk persistency, and SCS_I (Figure 3). Overall, the $R E$ calculated for MY indicators were larger than those calculated for LP indicators, with only few exceptions (Figure 3), and thus they are expected to be more efficient for improving these breeding-goal traits.

Functional longevity of cows is a complicated trait, affected by fertility, feet and leg disorders, and mastitis

Table 5. Heritability of traits describing changes over time ${ }^{1}$ in milk yield (MY, kg/d), SCS (units), and score of total somatic cells daily excreted in milk (TSCS, ${ }^{2}$ units); standard errors of heritability estimates were $<0.01$

\begin{tabular}{lccc}
\hline Heritability & MY & SCS & TSCS \\
\hline$\beta_{1}$ & 0.08 & 0.01 & 0.01 \\
$\beta_{2}$ & 0.11 & 0.02 & 0.01 \\
$\beta_{3}$ & 0.08 & 0.01 & 0.01 \\
$\beta_{12}$ & 0.10 & 0.03 & 0.03 \\
$\beta_{123}$ & 0.11 & 0.04 & 0.03 \\
$\beta_{23}$ & 0.03 & 0.01 & 0.01 \\
$\Delta_{12}$ & 0.07 & 0.03 & 0.02 \\
$\Delta_{13}$ & 0.09 & 0.04 & 0.03 \\
$\Delta_{23}$ & 0.01 & 0.01 & 0.01 \\
\hline
\end{tabular}

${ }^{1} \beta$ are slopes from a linear regression of the trait on DIM within or across lactations; $\Delta$ are deltas expressed as the difference between the means of the trait in the 2 lactations considered.

${ }^{2} \mathrm{TSCS}=\log _{2}(\mathrm{SCC} \times \mathrm{MY})$, where SCC is expressed in cells $/ \mathrm{mL}$ and $\mathrm{MY}$ in $\mathrm{mL} / \mathrm{d}$. susceptibility, among others. Several of these traits are known to be genetically related to MY and to changes in MY across parities. We hypothesized that changes in LP act as "mammary memory indicators" by providing information on past mammary infections, and in this way can act as indicators for part of the functional longevity index (i.e., the part of longevity related to udder health). As MY is related to more aspects of functional longevity, it was not surprising that indicators based on MY were more efficient in selection for functional longevity than those of LP. Furthermore, changes in LP and MY provide different information, as their $r_{C}$ was moderate (Table 4). Therefore, these results indicated that changes in LP can provide additional information in selection, possibly by reducing mastitis incidence, and in this way, indirectly improving a cow's productive life.

The $R E$ calculated does not account for possible effects on the generation interval. The $\beta_{1}$ would be available relatively early in the life of a cow, allowing selection of animals at a young age. Nevertheless, results showed that indicators covering more than 1 lactation (i.e., $\beta_{12}$ and $\Delta_{12}$ ) would be more efficient indicators as compared with $\beta_{1}$. This implies that information for selection will become available later in life. These consequences for the generation interval were not accounted for in our calculations of selection efficiency but are important for the selection response of a breeding program.

\section{Selection Bias}

For the purpose of the study, a selected sample from the population was analyzed, discarding cows that did not have second and third lactations (i.e., that did not have data in the first 3 lactations). This allowed calculating all LP indicators on the same set of cows. However, inclusion of information from cows culled (e.g., in parity 1) would probably result in a greater variability of some indicators. In the original data set, 207,740 cows (in 933 herds) had 5 TD in first lactation, but were not included in this study due to the lack of records in the subsequent 2 lactations. For these cows, the average $\beta_{1}$ for LP was -0.375 with a SD of 0.827 . This indicated that cows with only first-lactation TD, and none in later lactations, showed a stronger decrease in LP, since the average $\beta_{1}$ for LP of cows included in the present study was -0.318 with a SD of 0.772 (Table 2 ). This confirmed that a strong decrease of LP during first lactation is related to a higher probability of being culled. As a consequence of this selection, heritabilities presented in this study most likely underestimated the true heritability. Additional analyses based on cows with $\geq 5$ LP records only in first lactation $(\mathrm{n}=207,740)$, 

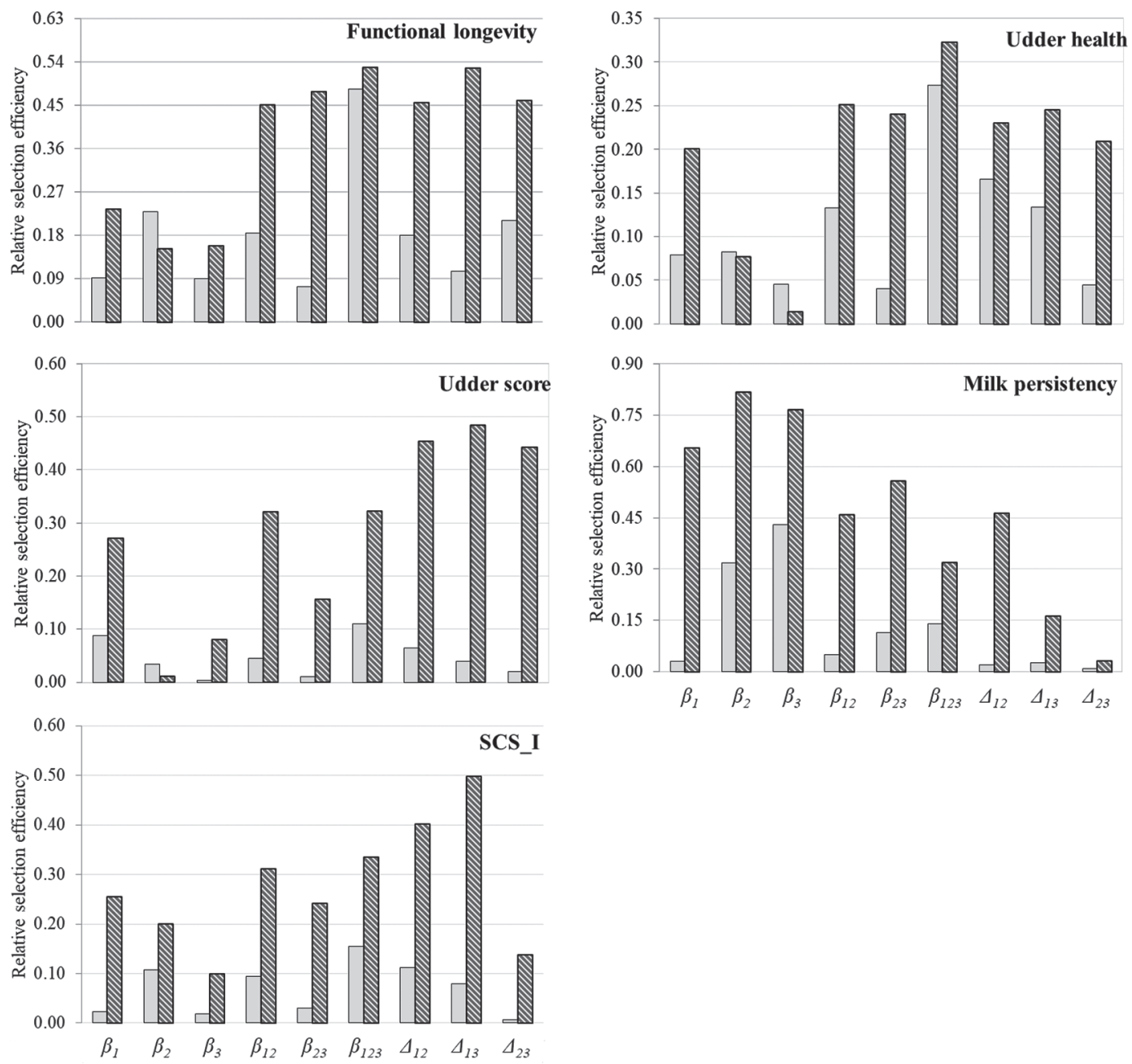

Figure 3. Relative selection efficiency in the different breeding goals with direct selection on traits describing changes over time in lactose percentage (solid bar) and milk yield (striped bar). Goals were functional longevity index, udder health index, udder score index, milk persistency, and SCS index (SCS_I). $\beta$ are slopes from a linear regression of the trait on DIM within or across lactations; $\Delta$ are deltas expressed as the difference between the means of the trait in the 2 lactations considered. All $\beta$ were multiplied by 1,000 to avoid convergence issues.

without considering subsequent lactations, resulted in a heritability of LP $\beta_{1}$ of 0.13 ( \pm 0.005 ; data not shown) which is higher than the reported heritability of 0.11 (Table 2). Selection can be accounted for in an animal model when all the information on which selection decisions are based is included in the analysis (Kennedy et al., 1988). If selection is based on first parity records, then by including these records and using multivariate analysis, the bias can be reduced (Pollak et al., 1984).

\section{Implementation}

The LP is routinely recorded in milk recording programs worldwide. Therefore, the use of changes in LP as indicator traits can be implemented without much additional effort. Similarly, as for persistency of MY, changes in LP can be estimated based on EBV obtained from multivariate random regression models. Such analyses would use the available data more efficiently and would limit potential bias due to selection, which affected results from the current study. However, before implementing selection for changes in LP, longitudinal data on clinical and subclinical mastitis infections (e.g., based on bacteriological data) is needed to confirm the hypothesis that changes in LP mirror the infection history of the mammary gland and can be considered a mammary memory indicator.

\section{CONCLUSIONS}

In the present study, 9 descriptors based on LP changes in milk over the first 3 lactations were studied to evaluate their potential use as indicators for selective breeding for longevity or udder health. Results 
showed that a larger decrease of LP during the productive life was indicative of reduced functional longevity, poorer udder conformation and health, and lower milk persistency. Among the 9 LP indicators, some were moderately heritable and genetically correlated with several functional traits. In terms of selection response, indicators based on data of 2 or more lactations (i.e., $\beta_{12}$ and $\Delta_{12}$ ) were more efficient when compared with changes in LP based on the first lactation $\left(\beta_{1}\right)$. The latter, however, can be available early in the productive life of the cow and would allow prompt choices and faster selection of animals. To the authors' knowledge, this is the first study into the use of changes in LP as indicators for breeding-goal traits in dairy cattle. These results are promising and warrant further research into the biological relation existing between milk LP, cumulative effects of udder infections, and mammary gland epithelial integrity.

\section{ACKNOWLEDGMENTS}

The Italian Holstein and Jersey Breeders Association (ANAFIJ, Cremona, Italy) is gratefully acknowledged for providing data. The authors want to thank Giulio Visentin (ANAFIJ, Cremona, Italy) for useful comments to improve the first draft of the manuscript. This study was supported by the University of Padova (Ricerca Scientifica fondi DOR-2017, project DOR1721792/17; Padua, Italy). The authors have not stated any conflicts of interest.

\section{REFERENCES}

Akers, R. M., and S. C. Nickerson. 2011. Mastitis and its impact on structure and function in the ruminant mammary gland. J. Mammary Gland Biol. Neoplasia 16:275-289. https://doi.org/10.1007/ s10911-011-9231-3.

ANAFIJ (Italian Holstein and Jersey Breeders Association). Index calculation cards. 2019. Accessed Mar. 15, 2020. http://www.anafij it/en/genetic-indexes/index-calculation-cards.

Bae, H., C. H. Jeong, W. N. Cheng, K. Hong, H. G. Seo, and S. G. Han. 2017. Oxidative stress-induced inflammatory responses and effects of $\mathrm{N}$-acetylcysteine in bovine mammary alveolar cells. J. Dairy Res. 84:418-425. https://doi.org/10.1017/S002202991700067X.

Berghof, T. V. L., M. Poppe, and H. Mulder. 2019. Opportunities to improve resilience in animal breeding programs. Front. Genet. 9:692. https://doi.org/10.3389/fgene.2018.00692.

Calo, L. L., R. E. McDowell, L. D. VanVleck, and P. D. Miller. 1973. Genetic aspects of beef production among Holstein-Friesians pedigree selected for milk production. J. Anim. Sci. 37:676-682. https: //doi.org/10.2527/jas1973.373676x.

Capuco, A. V., and R. K. Choudhary. 2020. Symposium review: Determinants of milk production: Understanding population dynamics in the bovine mammary epithelium. J. Dairy Sci. 103:2928-2940. https://doi.org/10.3168/jds.2019-17241.

Cole, J. B., and P. M. VanRaden. 2018. Possibilities in an age of genomics: The future of selection indices. J. Dairy Sci. 101:36863701. https://doi.org/10.3168/jds.2017-13335.

Costa, A., C. Egger-Danner, G. Mészáros, C. Fuerst, M. Penasa, J. Sölkner, and B. Fuerst-Waltl. 2019a. Genetic associations of lac- tose and its ratios to other milk solids with health traits in Austrian Fleckvieh cows. J. Dairy Sci. 102:4238-4248. https://doi.org/ 10.3168/jds.2018-15883.

Costa, A., N. Lopez-Villalobos, N. W. Sneddon, L. Shalloo, M. Franzoi, M. De Marchi, and M. Penasa. 2019b. Invited review: Milk lactose-Current status and future challenges in dairy cattle. J. Dairy Sci. 102:5883-5898. https://doi.org/10.3168/jds.2018-15955.

Costa, A., N. Lopez-Villalobos, G. Visentin, M. De Marchi, M. Cassandro, and M. Penasa. 2019c. Heritability and repeatability of milk lactose and its relationships with traditional milk traits, somatic cell score and freezing point in Holstein cows. Animal 13:909-916. https://doi.org/10.1017/S1751731118002094.

de Jong, G. 2014. Lifetime Production Index, what cows really can produce. Interbull Bull. 48:54-57. https://journal.interbull.org/ index.php/ib/article/view/1345.

Egger-Danner, C., J. B. Cole, J. E. Pryce, N. Gengler, B. Heringstad, A. Bradley, and K. F. Stock. 2015. Invited review: Overview of new traits and phenotyping strategies in dairy cattle with a focus on functional traits. Animal 9:191-207. https://doi.org/10.1017/ S1751731114002614.

Fox, P. F., T. Uniacke-Lowe, P. L. H. McSweeney, and J. A. O'Mahoni. 2015. Dairy Chemistry and Biochemistry. Springer International Publishing, Basel, Switzerland.

Garg, P. K. 2015. Large standard deviation: Think before you write. World J. Surg. 39:808-809. https://doi.org/10.1007/s00268-014 -2772-z.

Gilmour, A. R., B. J. Gogel, B. R. Cullis, S. J. Welham, and R. Thompson. 2015. ASReml User Guide. VSN Int. Ltd., Hemel Hempstead, UK. Accessed Aug. 24, 2020. https://www.vsni.co.uk.

Gottardo, P., M. Penasa, F. Righi, N. Lopez-Villalobos, M. Cassandro, and M. De Marchi. 2017. Fatty acid composition of milk from Holstein-Friesian, Brown Swiss, Simmental and Alpine Grey cows predicted by mid-infrared spectroscopy. Ital. J. Anim. Sci. 16:380389. https://doi.org/10.1080/1828051X.2017.1298411.

Grelet, C., A. Vanlierde, M. Hostens, L. Foldager, M. Salavati, K. L. Ingvartsen, M. Crowe, M. T. Sorensen, E. Froidmont, C. P. Ferris, C. Marchitelli, F. Becker, T. Larsen, F. Carter, and F. Dehareng. 2019. Potential of milk mid-IR spectra to predict metabolic status of cows through blood components and an innovative clustering approach. Animal 13:649-658. https://doi.org/10.1017/ S1751731118001751.

Haile-Mariam, M., and J. E. Pryce. 2017. Genetic parameters for lactose and its correlation with other milk production traits and fitness traits in pasture-based production systems. J. Dairy Sci. 100:3754-3766. https://doi.org/10.3168/jds.2016-11952.

Heringstad, B., D. Gianola, Y. M. Chang, J. Odegard, and G. Klemetsdal. 2006. Genetic associations between clinical mastitis and somatic cell score in early first-lactation cows. J. Dairy Sci. 89:2236-2244. https://doi.org/10.3168/jds.S0022-0302(06)72295 $-0$.

Herve, L., V. Lollivier, H. Quesnel, and M. Boutinaud. 2018. Oxytocin induces mammary epithelium disruption and could stimulate epithelial cell exfoliation. J. Mammary Gland Biol. Neoplasia 23:139-147. https://doi.org/10.1007/s10911-018-9400-8.

Herve, L., H. Quesnel, M. Veron, J. Portanguen, J. J. Gross, R. M. Bruckmaier, and M. Boutinaud. 2019. Milk yield loss in response to feed restriction is associated with mammary epithelial cell exfoliation in dairy cows. J. Dairy Sci. 102:2670-2685. https://doi.org/ $10.3168 /$ jds.2018-15398.

Interbull. 2020. National genetic evaluation forms provided by countries. Accessed Mar. 15, 2020. http://www.interbull.org/ib/ geforms.

Jamali, H., H. W. Barkema, M. Jacques, E.-M. Lavallée-Bourget, F. Malouin, V. Saini, H. Stryhn, and S. Dufour. 2018. Invited review: Incidence, risk factors, and effects of clinical mastitis recurrence in dairy cows. J. Dairy Sci. 101:4729-4746. https://doi.org/10.3168/ jds.2017-13730.

Jin, X., K. Wang, H. Liu, F. Hu, F. Zhao, and J. Liu. 2016. Protection of bovine mammary epithelial cells from hydrogen peroxideinduced oxidative cell damage by resveratrol. Oxid. Med. Cell. Longev. 2016:2572175. https://doi.org/10.1155/2016/2572175. 
Jóźwik, A., J. Krzyżewski, N. Strzałkowska, E. Poławska, E. Bagnicka, A. Wierzbicka, K. Niemczuk, P. Lipińska, and J. O. Horbańczuk. 2012. Relations between the oxidative status, mastitis, milk quality and disorders of reproductive functions in dairy cows - A review. Anim. Sci. Pap. Rep. 30:297-307.

Kennedy, B. W., L. R. Schaeffer, and D. A. Sorensen. 1988. Genetic properties of animal models. J. Dairy Sci. 71:17-26. https://doi .org/10.1016/S0022-0302(88)79975-0.

Miglior, F., A. Sewalem, J. Jamrozik, J. Bohmanova, D. M. Lefebvre, and R. K. Moore. 2007. Genetic analysis of milk urea nitrogen and lactose and their relationships with other production traits in Canadian Holstein cattle. J. Dairy Sci. 90:2468-2479. https://doi .org/10.3168/jds.2006-487.

Miglior, F., A. Sewalem, J. Jamrozik, D. M. Lefebvre, and R. K. Moore. 2006. Analysis of milk urea nitrogen and lactose and their effect on longevity in Canadian dairy cattle. J. Dairy Sci. 89:48864894. https://doi.org/10.3168/jds.S0022-0302(06)72537-1.

Pinzón-Sánchez, C., and P. L. Ruegg. 2011. Risk factors associated with short-term post-treatment outcomes of clinical mastitis. J. Dairy Sci. 94:3397-3410. https://doi.org/10.3168/jds.2010-3925.

Pollak, E. J., J. van der Werf, and R. L. Quaas. 1984. Selection bias and multiple trait evaluation. J. Dairy Sci. 67:1590-1595. https:// doi.org/10.3168/jds.S0022-0302(84)81481-2.
Poppe, M., R. F. Veerkamp, M. L. van Pelt, and H. Mulder. 2020. Exploration of variance, autocorrelation, and skewness of deviations from lactation curves as resilience indicators for breeding. J. Dairy Sci. 103:1667-1684. https://doi.org/10.3168/jds.2019-17290.

Shuster, D. E., R. J. Harmon, J. A. Jackson, and R. W. Hemken. 1991. Suppression of milk production during endotoxin-induced mastitis. J. Dairy Sci. 74:3763-3774. https://doi.org/10.3168/jds .S0022-0302(91)78568-8.

Stoop, W. M., J. A. M. van Arendonk, J. M. L. Heck, H. J. F. van Valenberg, and H. Bovenhuis. 2008. Genetic parameters for major milk fatty acids and milk production traits of Dutch HolsteinFriesians. J. Dairy Sci. 91:385-394. https://doi.org/10.3168/jds .2007-0181.

Zhao, X., and P. Lacasse. 2008. Mammary tissue damage during bovine mastitis: Causes and control. J. Anim. Sci. https://doi.org/ 10.2527/jas.2007-0302.

\section{ORCIDS}

A. Costa @ https://orcid.org/0000-0001-5353-8988

H. Bovenhuis @ https://orcid.org/0000-0002-9074-5334

M. Penasa ๑ https://orcid.org/0000-0001-9984-8738 